Physiology in aging

\title{
Targeted therapy for breast cancer in older patients
}

\author{
Noam Pondé ${ }^{\mathrm{a}, *}$, Hans Wildiers $^{\mathrm{b}}$, Ahmad Awada ${ }^{\mathrm{c}}$, Evandro de Azambuja ${ }^{\mathrm{a}}$, Coralie Deliens ${ }^{\mathrm{d}}$, Lissandra Dal Lago ${ }^{\mathrm{c}}$ \\ ${ }^{a}$ Medical Support Team, Institut Jules Bordet, Brussels, Belgium \\ b Department of General Medical Oncology, University Hospitals Leuven, Leuven, Belgium \\ c Department of Medicine, Institut Jules Bordet, Brussels, Belgium \\ d Pharmacy Department, Institut Jules Bordet, Brussels, Belgium
}

\section{A R T I C L E I N F O}

\section{Article history:}

Received 21 December 2018

Received in revised form 25 March 2019

Accepted 14 May 2019

Available online $\mathrm{xxxx}$

\section{Keywords:}

Breast cancer

Older patients

Targeted agents

Adverse events

Geriatric oncology

\begin{abstract}
A B S T R A C T
Older patients are one of the most relevant sub-groups of patients with breast cancer and will only gain in importance as demographic transition unfolds. Their management, in both the early and advanced settings, should take into consideration specific clinical needs and is made more difficult by the limited availability of evidence on the efficacy and safety of standard treatment regimens in older patients. At the root of this situation is the low rate of participation of older patients in clinical trials, often due to age limits for inclusion, and limitations on the participation of persons with significant comorbidities or organ dysfunction. Although this has begun to change in recent years, most agents currently in use have not been tested in a substantial number of older patients. This includes the targeted agents that have, in the last fifteen years, changed the prognosis of patients with early and advanced breast cancer. Most data guiding the use of targeted agents in older patients come from subanalysis of larger trials or small retrospective cohort studies. The goal of this review is to go over the available evidence regarding the efficacy and safety of targeted agents approved for use in breast cancer (trastuzumab, lapatinib, T-DM1, pertuzumab, neratinib, palbociclib, bevacizumab, ribociclib, abemaciclib, everolimus, olaparib, talazoparib), and place their side effects into an older-specific context in order to help medical oncologists when making treatment decisions and managing older patients with breast cancer.
\end{abstract}

(c) 2019 Elsevier Ltd. All rights reserved.

\section{Contents}

1. Introduction . . . . . . . . . . . . . . . . . . . . . . . . . . . . . . . . . . . . . . . . . . . . . . 0

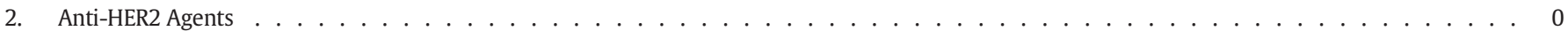

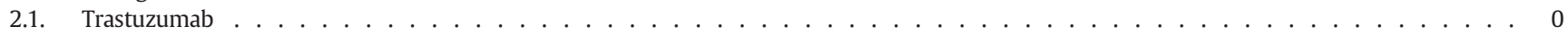

2.1.1. Metastatic Setting . . . . . . . . . . . . . . . . . . . . . . . . . . . . . . . . . . 0

2.1.2. Adjuvant Setting. . . . . . . . . . . . . . . . . . . . . . . . . . . . . . . . . . . . 0

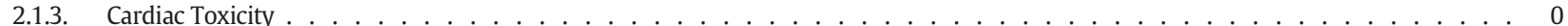

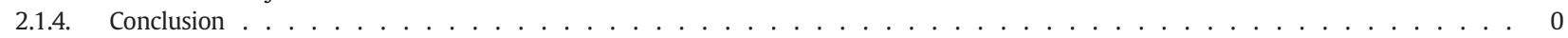

2.2. Lapatinib . . . . . . . . . . . . . . . . . . . . . . . . . . . . . . . . . 0

2.3. Pertuzumab. . . . . . . . . . . . . . . . . . . . . . . . . . . . . . . . . . . 0

2.3.1. Metastatic Setting . . . . . . . . . . . . . . . . . . . . . . . . . . . . . . . . . 0

2.3.2. Early Setting . . . . . . . . . . . . . . . . . . . . . . . . . . . . . . . . . . 0

2.4. Trastuzumab-emtansine (T-DM1) . . . . . . . . . . . . . . . . . . . . . . . . . . . . . . . . . . . . . . . . . 0

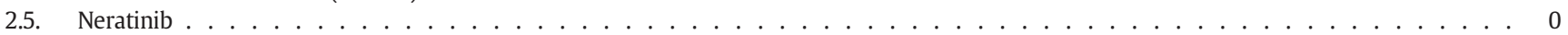

3. mTOR Inhibitors . . . . . . . . . . . . . . . . . . . . . . . . . . . . . . . . . . . . . . . . . . . . . . . . . . . . . . 0

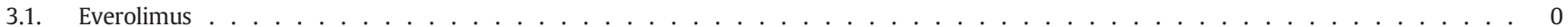

4. Anti-angiogenics . . . . . . . . . . . . . . . . . . . . . . . . . . . . . . . . . . . . . . 0

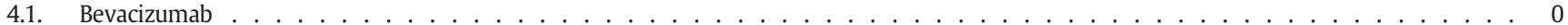

5. CDK 4/6 Inhibitors . . . . . . . . . . . . . . . . . . . . . . . . . . . . . . . . . . . . . . . . . . . . . . . . . . . . 0

5.1. Palbociclib. . . . . . . . . . . . . . . . . . . . . . . . . . . . . . . . . . 0.

\footnotetext{
* Corresponding author at: Blvd de Waterloo, 121, 1000 Brussels, Belgium.

E-mail address: noamponde@accamargo.or.br (N. Pondé).
} 


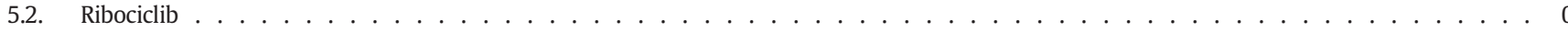

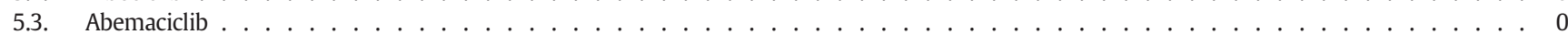

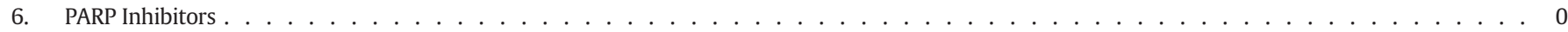

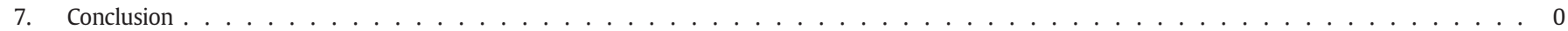

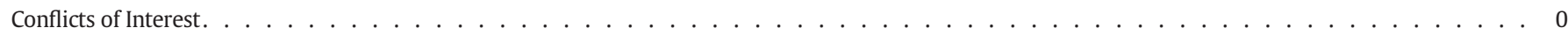

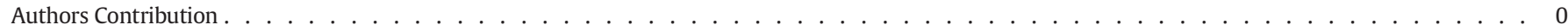

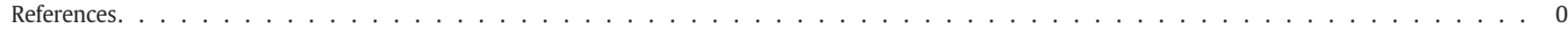

\section{Introduction}

Breast cancer (BC) is one of the most frequent and deadly forms of cancer [1]. Older patients represent, today, a large proportion of patients in diagnosed with $\mathrm{BC}$ [2]. Evidence-based management of older patients with $\mathrm{BC}$ is challenging as they are underrepresented in clinical trials $[3,4]$. End-points used in cancer trials, moreover, can be less relevant to older patients, who often focus on functionality rather than on increasing survival time $[5,6]$. Registration trials rarely focus on issues specific to older patients or place drug safety within a context appropriate to older patients, including investigating interactions, altered drug metabolism and what toxicity may entail for older patients. Today, due to the rarity of studies designed to study targeted agents in older populations, most of the efficacy and safety data which underpin treatment decisions is based on small case series, retrospective cohorts or sub-analysis of general population studies.

This review will provide a thorough and practical expert opinionbased assessment of the state of the evidence regarding approved targeted agents in older patients with BC (Tables 1 and 2). Particular attention will be given to drug-related adverse events (AEs), in putting the most clinically relevant AEs into a geriatric context (Supplementary Table 1), highlighting the special concerns that may arise due to common AEs in older patients as well as on potential drug-drug interactions (Table 3 ) in order to help medical oncologists make the most appropriate decisions.

\section{Anti-HER2 Agents}

Anti-human epidermal growth factor receptor 2 (HER2) agents comprise five agents, approved in the early and/or advanced setting $[7,8]$. These are trastuzumab, lapatinib, pertuzumab, T-DM1 and neratinib (see Table 1 ).

\subsection{Trastuzumab}

\subsubsection{Metastatic Setting}

Data on the efficacy and safety of trastuzumab in older patients in the metastatic setting is sparse. Kaufman et al. compared patients aged $\geq 75$ ( 65 patients) with those aged between $\geq 65$ and $<75$ ( 144 patients) and those aged $<65$ (792 patients). Results suggest that the patients $\geq 75$ receive trastuzumab less frequently ( $77 \%$ vs $81 \%$ vs $85 \%$, respectively) and are more likely to receive it alone or in combination with endocrine therapy (ET) (18\% vs $4.3 \%$ vs $5.3 \%$ respectively) [9]. Another study by Griffiths et al. used SEER-MEDICARE database data to identify 610 patients $\geq 66$ years who received trastuzumab for metastatic BC. Their results suggest trastuzumab use is associated with reduced cancer-specific mortality (HR $0.67 ; 95 \% \mathrm{CI} 0.51-0.88 P<.01$ ). Interestingly, in this study, $31 \%$ of patients received trastuzumab alone while $48 \%$ received trastuzumab plus taxane-based chemotherapy (which was significantly associated with better outcomes) [10].

\subsubsection{Adjuvant Setting}

One meta-analysis of the adjuvant trials and one systematic review investigated outcomes in older (defined as $\geq 60$ ) patients who participated in trastuzumab adjuvant trials and both publications show significant improvement in outcomes with the use of trastuzumab $[11,12]$. Additional data is available from retrospective cohort studies. The study by Dall et al. showed patients aged $\geq 65$ had similar improvement in outcomes but a higher risk of early discontinuation ( $8 \%$ in $<65$ and $13 \% \geq 75$ ) and probability of receiving trastuzumab monotherapy ( $5 \%$ in $<65$ and $9 \% \geq 75$ ) when compared to younger patients [13]. Reeder-Hayes et al. investigated the comparative efficacy and toxicity of adjuvant regimens containing trastuzumab in older patients using SEER-Medicare data, showing that the two most commonly prescribed regimens - ACTH (doxorubicin, cyclophosphamide, paclitaxel, and trastuzumab) and TCH (docetaxel, carboplatin, and trastuzumab) led to comparably good survival outcomes in older patients. ACTH compared with TCH was, moreover, not associated with a higher rate of serious AEs or hospitalizations, but was associated with worse treatment completion [14].

One study prospectively evaluated trastuzumab in older patients the RESPECT trial (NCT01104935), which randomized 275 patients between 70 and 80 years of age with stage I-IIIA HER2 + BC between adjuvant trastuzumab alone or trastuzumab plus chemotherapy. The goal of RESPECT was to determine whether trastuzumab monotherapy was non-inferior to trastuzumab + chemotherapy in older patients. Threeyear disease-free survival (DFS) results were 94.8\% (combination) vs 89.2\% (trastuzumab alone), HR 1.42; 95\% CI 0.68-2.95, $p=.35$. Trastuzumab monotherapy was better tolerated and was on the short term better in terms of quality of life (QoL), though no difference remained at three years, including, critically, on cognitive function [15-17]. The results are difficult to interpret since the study was clearly underpowered to confirm non-inferiority with clinically relevant borders.

The duration of adjuvant treatment with trastuzumab has been long debated [18]. Several trials had tested reduced treatment durations, all having failed until very recently [19]. The PERSEPHONE trial testing one year vs six months of trastuzumab showed non-inferiority between efficacy outcomes with the two regimens. Though the results of PERSEPHONE should be seen with caution, six month trastuzumab treatment could be considered as an option in older patients when

Table 1

FDA and/or EMA Approved target agents for use in breast cancer treatment.

\begin{tabular}{lll}
\hline Name & $\begin{array}{l}\text { Year of } \\
\text { Approval }\end{array}$ & Settings \\
\hline Trastuzumab & 1998 & Early and Metastatic HER2+ Disease \\
Lapatinib & 2007 & Metastatic HER2+ Disease \\
Bevacizumab & 2010 & Metastatic HER2- Disease $^{\mathrm{b}}$ \\
Everolimus & 2010 & Metastatic ER+ HER2- Disease \\
Pertuzumab & 2012 & Early and Metastatic HER2+ Disease \\
T-DM1 & 2013 & Early and Metastatic HER2 + Disease \\
Palbociclib & 2015 & Metastatic ER+ HER2- Disease \\
Ribociclib & 2017 & Metastatic ER+ HER2- Disease \\
Neratinib & 2017 & Early HER2+ Disease \\
Olaparib & 2018 & Metastatic HER2- Disease in gBRCA mutated patients \\
Talazoparib & 2018 & Metastatic HER2- Disease in gBRCA mutated patients \\
\end{tabular}

FDA - Food and Drug Administration; EMA - European Medicines Agency; HER2 -human epidermal growth factor receptor 2; ER - Estrogen Receptor, gBRCA - Germline Breast Cancer Susceptibility Gene.

a FDA approved only.

b EMA approved only. 
Table 2

Phase III trials and reported older adult populations and results.

\begin{tabular}{|c|c|c|c|c|c|}
\hline Drug & Trial & Indication & Treatment & Older population & Reported results in older adults \\
\hline Trastuzumab & $\begin{array}{l}\text { TAnDEM } \\
(\text { NCT00022672) } \\
{[92]}\end{array}$ & Metastatic & Trastuzumab+Anastrozole vs Anastrozole & Not reported. & Not reported \\
\hline Trastuzumab & Slamon Trial [93] & Metastatic & Trastuzumab + CT vs CT & Not reported. & Not Reported \\
\hline Trastuzumab & $\begin{array}{l}\text { HERA } \\
(\text { NCT00045032) } \\
{[94]}\end{array}$ & Adjuvant & $\begin{array}{l}\text { Trastuzumab } 1 \text { year vs Trastuzumab } 2 \text { years vs } \\
\text { Observation }\end{array}$ & $\geq 60=818(16 \%)$ & $\begin{array}{l}\geq 601 \mathrm{y} \text { vs observation DFS HR }=0.82(\mathrm{CL}, \\
0.62-1.08) ; 2 \mathrm{y} \text { vs observation } \mathrm{HR} 0,78(\mathrm{CL} \text {, } \\
0.59-1.03)\end{array}$ \\
\hline Trastuzumab & $\begin{array}{l}\text { BCIRG-006 } \\
(\text { NCT00021255) } \\
{[95]}\end{array}$ & Adjuvant & AC-T vs AC-TH vs TCH ( 1 year of trastuzumab) & Not reported. & Not Reported \\
\hline Trastuzumab & $\begin{array}{l}\text { NCCTG N9831 + } \\
\text { NSABP B31 }\end{array}$ & Adjuvant & AC-T vs AC-TH ( 1 year of trastuzumab) & $\geq 60=683(16.8 \%)$ & $>60$ DFS HR $=0.41(95 \% \mathrm{CI}, 0.24-0.68)$ \\
\hline Trastuzumab & $\begin{array}{l}\text { FNCLCC-PACS } 04 \\
{[96]}\end{array}$ & Adjuvant & $\mathrm{CT}+$ Trastuzumab vs CT ( 1 year of trastuzumab) & $\begin{array}{l}\text { No patients above } 65 \\
\text { allowed, above } 60 \\
\text { not reported }\end{array}$ & Not reported \\
\hline Trastuzumab & FinHER [18] & Adjuvant & $\begin{array}{l}\text { Docetaxel or Vinorelbine with or without } \\
\text { Trastuzumab for } 9 \text { weeks }\end{array}$ & $\begin{array}{l}\text { No patients above } 65 \\
\text { allowed, above } 60 \\
\text { not reported }\end{array}$ & Not reported \\
\hline Pertuzumab & $\begin{array}{l}\text { CLEOPATRA } \\
\text { (NCT00567190) } \\
{[37]}\end{array}$ & Metastatic & $\begin{array}{l}\text { Docetaxel+Trastuzumab+Pertuzumab vs } \\
\text { Docetaxel+Trastuzumab+Placebo }\end{array}$ & $\begin{array}{l}\geq 65=127(15,7 \%) \\
\geq 75=19(2,3 \%)\end{array}$ & $\begin{array}{l}\mathrm{PFS} \geq 65 \text { HR } 0,53(\mathrm{CI} 0,31-0,9) ; \geq 75 \text { HR } 0,85 \\
(\mathrm{CI} 0,26-2,73)\end{array}$ \\
\hline Pertuzumab & $\begin{array}{l}\text { Neosphere } \\
\text { (NCT00545688) } \\
{[44]}\end{array}$ & Neoadjuvant & $\begin{array}{l}\text { Docetaxel+Trastuzumab; Pertuzumab+Docetaxel; } \\
\text { Pertuzumab+Trastuzumab, Docetaxel } \\
\text { +Trastuzumab+Pertuzumab }\end{array}$ & Not reported. & Not Reported \\
\hline Pertuzumab & $\begin{array}{l}\text { APHINITY } \\
\text { (NCT01358877) } \\
{[46]}\end{array}$ & Adjuvant & $\begin{array}{l}\mathrm{CT}+\text { Trastuzumab }+ \text { Pertuzumab vs } \mathrm{CT}+ \\
\text { Trastuzumab }+ \text { placebo }\end{array}$ & $\geq 65=608(12.6 \%)$ & $\begin{array}{l}\geq 65=3 y-I D F S \text { 92,9\% vs } 90,6 \% \text { HR } 0,70 \\
(\text { CI0,41-1,17) }\end{array}$ \\
\hline T-DM1 & $\begin{array}{l}\text { EMILIA } \\
\text { (NCT00829166) } \\
{[48]}\end{array}$ & Metastatic & T-DM1 vs Capecitabine + Lapatinib & $\begin{array}{l}65-74=113 \\
(11,4 \%) ; \geq 75=25 \\
(2,5 \%)\end{array}$ & $\begin{array}{l}\text { 65-74 HR 0,89 (CI 0,56-1,43); } \geq 75 \text { HR } 2,79 \\
(0,99-7,88)\end{array}$ \\
\hline T-DM1 & $\begin{array}{l}\text { TH3RESA } \\
\text { (NCT01419197) } \\
{[49]}\end{array}$ & Metastatic & T-DM1 vs Physicians choice & $\begin{array}{l}65-74=74(12,9 \%) \\
\geq 75=19(3,1 \%)\end{array}$ & $\begin{array}{l}\text { OS: } 65-74=18,2 \mathrm{~m} \text { vs } 13,5 \mathrm{~m}(\mathrm{HR} 0,73 \mathrm{Cl} \\
0,40-1,34) ; \geq 75=31,8 \mathrm{~m} \text { vs } 16,4 \mathrm{~m}(\mathrm{HR} \\
0,27 \mathrm{Cl} 0,07-1,04)\end{array}$ \\
\hline T-DM1 & $\begin{array}{l}\text { KATHERINE } \\
\text { (NCT01772472) } \\
{[50]}\end{array}$ & Post-neoadjuvant & T-DM1 vs Trastuzumab & $\begin{array}{l}65-74=56(7.5 \%) \\
\geq 75=2(0.3)\end{array}$ & $\begin{array}{l}\text { iDFS } \geq 65=87.4 \% \text { vs } 81.1 \% \text { HR } 0.55(\mathrm{CI} \\
0.22-1.34)\end{array}$ \\
\hline Lapatinib & $\begin{array}{l}\text { Geyer Trial [30] } \\
\text { (NCT00078572) }\end{array}$ & Metastatic & Lapatinib+Capecitabine vs Capecitabine & Not reported. & Not Reported \\
\hline Lapatinib & $\begin{array}{l}\text { MA.31 } \\
\text { (NCT00667251) } \\
{[97]}\end{array}$ & Metastatic & Paclitaxel+Lapatinib vs Paclitaxel+Trastuzumab & $\begin{array}{l}60-69=143(22 \%) \\
\geq 70=60(9 \%)\end{array}$ & Not Reported \\
\hline Lapatinib & $\begin{array}{l}\text { EGF104900 } \\
\text { (NCT00320385) } \\
{[29]}\end{array}$ & Metastatic & Lapatinib+Trastuzumab vs Trastuzumab & Not reported. & Not Reported \\
\hline Lapatinib & ALTTO [32] & Adjuvant & $\begin{array}{l}\text { CT }+ \text { Trastuzumab vs CT }+ \text { Lapatinib vs } \mathrm{CT}+ \\
\text { Trastuzumab + Lapatinib vs CT }+ \\
\text { Trastuzumab-Lapatinib }\end{array}$ & $\geq 65=855(10 \%)$ & Not Reported \\
\hline Neratinib & $\begin{array}{l}\text { ExteNET } \\
(\text { NCT00878709) } \\
{[56]}\end{array}$ & Adjuvant & Neratinib + Paclitaxel vs Trastuzumab+Paclitaxel & $\geq 65=87(18 \%)$ & IDFS $\geq 65$ (HR 0,75 CI 0,43-1,30) \\
\hline Everolimus & $\begin{array}{l}\text { BOLERO-2 } \\
(\text { NCT00863655) } \\
{[63,98]}\end{array}$ & Metastatic & Everolimus+Examestane vs Placebo+Examestane & $\begin{array}{l}\geq 65=275 ; \geq 70= \\
164\end{array}$ & $\begin{array}{l}\text { PFS } \geq 70: 6,8 \text { vs } 1,5 \mathrm{~m} 0,45(0,30-0,68) \text {; } \\
\text { stomatitis } 49 \% \text {, fatigue } 38 \% \text {, decreased } \\
\text { appetite } 38 \% \text {, diarrhea } 36 \%\end{array}$ \\
\hline Palbociclib & $\begin{array}{l}\text { PALOMA - } 2 \\
(\text { NCT01740427) } \\
{[78,80]}\end{array}$ & Metastatic & Letrozole+Palbociclib vs Letrozole + Placebo & $\geq 65=262(39.3 \%)$ & $\begin{array}{l}\text { PFS } \geq 65: 26,2 \text { vs } 12,9 \mathrm{~m} \text { HR } 0.57(\mathrm{CI} \\
0,39-0,84)\end{array}$ \\
\hline Palbociclib & $\begin{array}{l}\text { PALOMA - } 3 \\
(\text { NCT01942135) } \\
{[80,99]}\end{array}$ & Metastatic & Fulvestrant + Palbociclib vs Fulvestrant + Placebo & $\geq 65=129(24,8 \%)$ & $\begin{array}{l}\text { PFS } \geq 65: 9,9 \text { vs } 3,9 \text { m HR } 0.35 \text { (CI } \\
0,19-0,62)\end{array}$ \\
\hline Ribociclib & $\begin{array}{l}\text { MONALEESA - } 2 \\
(\text { NCT01958021) } \\
{[83,100]}\end{array}$ & Metastatic & Ribociclib+Letrozole vs Letrozole & $\geq 65=295(44,2 \%)$ & PFS $\geq 65:$ HR $0,61(0,39-0,94)$ \\
\hline Bevacizumab & $\begin{array}{l}\text { AVADO } \\
(\text { NCT00333775) } \\
{[70,71]}\end{array}$ & Metastatic & $\begin{array}{l}\text { Placebo+Docetaxel vs Docetaxel+Bevacizumab } 7.5 \\
\text { mg vs Docetaxel+Bevacizumab } 15 \mathrm{mg}\end{array}$ & $\geq 65=127(17,2 \%)$ & $\begin{array}{l}\mathrm{PFS} \geq 65 \text {, placebo vs bev } 7,5 \mathrm{mg} \text { HR } 0,83 \text {; } \\
\text { placebo vs bev } 15 \mathrm{mg} \text { HR } 0,58, \mathrm{CI} \text { not } \\
\text { reported but both non-significant. }\end{array}$ \\
\hline Bevacizumab & $\begin{array}{l}\text { Ribbon-1 } \\
\text { (NCT00262067) } \\
{[101]}\end{array}$ & Metastatic & $\begin{array}{l}\text { Capecitabine or AT + Placebo vs Capecitabine or AT } \\
+ \text { Bevacizumab }\end{array}$ & $\begin{array}{l}\text { Capecitabine } \geq 65= \\
153(24,8 \%) ; \text { AT } \geq 65 \\
=124(19,9 \%)\end{array}$ & $\begin{array}{l}\text { Capecitabine } \geq 65 \text { PFS } 6,2 \text { vs } 9,1 \mathrm{~m} \text { (HR } 0,69 \\
95 \% \text { CI } 0,47-1,02) ; \text { AT } \geq 65 \text { PFS } 8,5 \text { vs } 10,1 \\
m(\text { HR } 0,8395 \% \text { CI } 0,52-1,34)\end{array}$ \\
\hline Bevacizumab & $\begin{array}{l}\text { E2100 } \\
(\text { NCT00028990) } \\
{[102]}\end{array}$ & Metastatic & Paclitaxel vs Paclitaxel+Bevacizumab & $\begin{array}{l}\geq 65-85=148(20 \\
49 \%)\end{array}$ & $\begin{array}{l}\mathrm{PFS} \geq 65-85: 7,9-11,9 \mathrm{~m} ; \mathrm{HR} 0,77(95 \% \mathrm{CI} \\
0,54-1,09)\end{array}$ \\
\hline Olaparib & $\begin{array}{l}\text { OlympiAD } \\
\text { (NCT02000622) } \\
{[87]}\end{array}$ & Metastatic & Olaparib vs Physicians Choice & $\begin{array}{l}15 \text { patients } 65 \text { or } \\
\text { older }(4.9 \%)\end{array}$ & Not reported \\
\hline
\end{tabular}


Table 2 (continued)

\begin{tabular}{|c|c|c|c|c|c|}
\hline Drug & Trial & Indication & Treatment & Older population & Reported results in older adults \\
\hline Talazoparib & $\begin{array}{l}\text { EMBRACA } \\
(\text { NCT01945775) } \\
{[88]}\end{array}$ & Metastatic & Talazoparib vs Physicians Choice & Not reported & Not reported \\
\hline
\end{tabular}

HR = Hazard Ratio, PFS = Progression Free-Survival, iDFS = invasive Disease Free Survival, OS = Overall Survival; DFS = Disease Free Survival.

anthracycline/taxane chemotherapy will be used [20]. It is important to stress, however, that chemotherapy de-escalation, as per the APT trial, should take precedence over trastuzumab de-escalation in older patients [21].

\subsubsection{Cardiac Toxicity}

Trastuzumab-induced cardiotoxicity is a special concern in older patients [22] and can lead to loss in functionality. It is, however, often asymptomatic and generally resolves after interruption of trastuzumab use [23] but whether this is also true for frail older patients is not specifically studied. Recognized risk factors include age (specially above 80), duration of treatment, comorbidities (hypertension, diabetes, coronary disease), and previous anthracycline use [23-25]. Most available studies in older patients receiving trastuzumab in either the metastatic and early settings confirm that they are at higher risk of experiencing trastuzumab-related cardiac toxicity, with rates of up to $25.4 \%$ of treated patients [9-11,13,26,27].

\subsubsection{Conclusion}

Though the amount of data available in clinical trials for trastuzumab use in older patients is overall limited, it suggests that trastuzumab is effective in older populations in both early and metastatic settings and that trastuzumab monotherapy is a sub-optimal regimen that should not be considered as standard. Risk factors for trastuzumab-associated cardiac toxicity are well established, allowing for easier patient selection. Fit older patients with controlled cardiovascular comorbidities and without end-organ damage are good candidates for trastuzumab therapy. For less fit or frail patients, trastuzumab therapy can still be, nevertheless, of benefit, with de-escalated regimens being an option in parallel with careful follow-up.

\subsection{Lapatinib}

Lapatinib is a tirosine kinase inhibitor that blocks HER1 and HER2 and is approved for use in combination with letrozole, capecitabine or trastuzumab in metastatic HER2 + BC [28-30]. Limited data is available

Table 3

Targeted drugs and interactions with commonly use drugs

\begin{tabular}{|c|c|c|c|}
\hline $\begin{array}{l}\text { Targeted } \\
\text { agent }\end{array}$ & Metabolism & Dose adjustments & Interactions \\
\hline Trastuzumab & Plasmatic & $\begin{array}{l}\text { No adjustments suggested for hepatic and renal } \\
\text { dysfunction (not studied) }\end{array}$ & $\begin{array}{l}\text { Increased cardiac toxicity with anthracycline use (wash } \\
\text { out } 20 \text { weeks for trastuzumab) }\end{array}$ \\
\hline Lapatinib & $\begin{array}{l}\text { Major substrate of CYP3A4, moderate } \\
\text { inhibitor of BCRP, CYP2C } 8 \text { and weak } \\
\text { inhibitor of CYP3A4 and } \\
\text { P-Glycoprotein }\end{array}$ & $\begin{array}{l}\text { Renal failure: As renal elimination is minimal therefore no } \\
\text { adjustment is needed; Hepatic failure: Child-Pugh class C } \\
\text { should have dose adjustment. With capecitabine dose } \\
\text { should be reduced } 750 \mathrm{mg} \text { and with letrozole } 1000 \mathrm{mg} \text {. }\end{array}$ & $\begin{array}{l}\text { To avoid: CYP 3A4, 2C8, } 2 \text { C19 (grapefruit juice) inhibitors, } \\
\text { inducers and substrates with a narrow therapeutic index, } \\
\text { substances that increase gastric pH (avoid oral anti-acids } \\
\text { within one-hour of a lapatinib dose), digoxin. Administer } \\
\text { with caution when prescribing medications that can } \\
\text { worsen heart function or increase QTc }\end{array}$ \\
\hline Pertuzumab & Plasmatic & $\begin{array}{l}\text { No adjustments suggested for hepatic and renal } \\
\text { dysfunction (not studied) }\end{array}$ & $\begin{array}{l}\text { To avoid: other monoclonal antibodies and } \\
\text { immunosuppressant medications }\end{array}$ \\
\hline T-DM1 & Major substrate of CYP3A4 & $\begin{array}{l}\text { No adjustments suggested for hepatic and renal } \\
\text { dysfunction (not studied) }\end{array}$ & $\begin{array}{l}\text { Close watch to patients receiving anticoagulants. Inhibitors } \\
\text { and inducers of 3A4 should be avoided, as well as PGP } \\
\text { inhibitors. }\end{array}$ \\
\hline Neratinib & $\begin{array}{l}\text { Major substrate of CYP3A4; Inhibitor } \\
\text { of P-glycoprotein/ABCB1 }\end{array}$ & $\begin{array}{l}\text { No dose adjustment needed. If severe hepatic function } \\
\text { impairment reduce dose to } 80 \mathrm{mg} / \text { day }\end{array}$ & $\begin{array}{l}\text { Close watch to patients receiving anticoagulants. Inhibitors } \\
\text { and inducers of 3A4 should be avoided, as well as PGP } \\
\text { inhibitors. }\end{array}$ \\
\hline Everolimus & $\begin{array}{l}\text { Major substrate of CYP3A4; Inhibitor } \\
\text { of P-glycoprotein/ABCB1, weak } \\
\text { inhibitor of CYP3A4 }\end{array}$ & $\begin{array}{l}\text { No adjustment needed for renal impairment. Dose should } \\
\text { be reduced to } 7,5 \mathrm{mg} \text { if mild impairment, } 5 \mathrm{mg} \text { if moderate } \\
\text { and } 2,5 \mathrm{mg} \text { if severe. }\end{array}$ & $\begin{array}{l}\text { Drugs that increase stomach } \mathrm{pH} \text { can alter absorption and } \\
\text { reduce efficacy. If anti-acid use is necessary take neratinib } \\
3 \mathrm{~h} \text { before. Inhibitors and inducers of } 3 \mathrm{~A} 4 \text { should be } \\
\text { avoided, as well as PGP/ABCB1 inhibitors and digoxin }\end{array}$ \\
\hline Palbociclib & $\begin{array}{l}\text { Major substrate of CYP3A4; weak } \\
\text { inhibitor of CYP3A4, Inhibitor of PGP }\end{array}$ & No dose adjustments for renal or liver failure & $\begin{array}{l}\text { Inhibitors, inducers and substrates of CYP } 3 \text { A } 4 \text { should be } \\
\text { avoided. Also avoid in patients with galactose intolerance, } \\
\text { Lapp lactase deficiency or glucose/galactose malabsorption } \\
\text { syndrome. }\end{array}$ \\
\hline Ribociclib & $\begin{array}{l}\text { Major substrate of CYP3A4; moderate } \\
\text { inhibitor of CYP3A4 }\end{array}$ & $\begin{array}{l}\text { No dose adjustments for renal failure, reduce dose to } 400 \\
\text { mg/day if moderate or severe liver impairment }\end{array}$ & $\begin{array}{l}\text { Avoid substrates, inducers and inhibitors of CYP 3A4 } \\
\text { (moderate inhibition CYP3A4) }\end{array}$ \\
\hline Bevacizumab & Plasmatic; Inhibitor of PGP & No dose adjustments for renal or liver failure & $\begin{array}{l}\text { Can increase the toxicity of anthracyclines and } \\
\text { myelosupressive effects of other cytotoxic agents. }\end{array}$ \\
\hline Abemaciclib & Substrate of CYP3A4. & $\begin{array}{l}\text { No dose adjustment necessary for renal failure; Child-Pugh } \\
\text { class C: Reduce the abemaciclib frequency to once daily. }\end{array}$ & $\begin{array}{l}\text { Avoid substrates, inducers and inhibitors of BCRP/ABCG2, } \\
\text { CYP3A4 and PGP/ABCB1 }\end{array}$ \\
\hline Olaparib & Substrate of CYP3A; Inhibitor of PGP & $\begin{array}{l}\text { Dose adjustment for } \mathrm{CrCl} \text { below } 50 \mathrm{~mL} / \mathrm{min} \text {. No } \\
\text { adjustments for moderate or mild liver failure. }\end{array}$ & $\begin{array}{l}\text { Avoid inhibitors and inducers of CYP3A4 as well as } \\
\text { substrates. If a moderate inhibitor of CYP3A4 is absolutely } \\
\text { necessary, dose should be reduced to either } 300 \mathrm{mg} \\
\text { (moderate) or } 200 \mathrm{mg} \text { (strong) }\end{array}$ \\
\hline Talazoparib & $\begin{array}{l}\text { Substrate of BCRP/ABCG2, } \\
\text { P-glycoprotein/ABCB1 }\end{array}$ & $\begin{array}{l}\mathrm{CrCl} 30 \text { to } 59 \mathrm{~mL} / \mathrm{min} \text { : Reduce dose to } 0.75 \mathrm{mg} \text { once daily. } \\
\text { No need of adjustment for mild liver function impairment, } \\
\text { not studies in moderate to serious liver function } \\
\text { impairment }\end{array}$ & $\begin{array}{l}\text { P-glycoprotein/ABCB1 Inhibitors such as Amiodarone; } \\
\text { Carvedilol; Clarithromycin; Itraconazole; Verapamil may } \\
\text { increase the concentration of talazoparib. In case of } \\
\text { concomitant use reduce talazoparib to } 0.75 \mathrm{mg} \text { per day for } \\
\text { the first 3-5 half lives }\end{array}$ \\
\hline
\end{tabular}


on lapatinib use in older patients with BC. A series of 26 cases above age 65 showed a median progression-free survival (PFS) of seven months with lapatinib and capecitabine (close to the 8.4 months improvement in time to progression obtained in the registration trial) [31]. Though in this series, lapatinib was overall reasonably well tolerated with only two interruptions due to AEs and only one treatment discontinuation due to adverse event, this has not been the case in the adjuvant setting in which tolerability and treatment completion rates are major concerns [35]. More recently, a prospective study in older patients ( $N=40$, median age 72) testing trastuzumab + lapatinib in the advanced setting showed a response rate of $23 \%$ and a clinical benefit rate of $45 \% .43 \%$ of patients needed a lapatinib dose reduction, and $20 \%$ had grade 3 or more AEs (diarrhea 5\%) [33].

In combination with capecitabine, lapatinib increases the incidence of diarrhea and cutaneous rash [28,29,31,32]. Clinical tools for predicting the toxicity of this regimen were proposed, and advanced age ( $>65)$ is a known risk factor [34]. It is, moreover, a regimen that entails the intake of numerous pills or tablets per day, and is therefore cumbersome and can lead to confusion and wrong dosing [35]. Considering the existing regimen choices, the favored regimens in older patients with hormone receptor positive tumors should be in combination with trastuzumab or letrozole.

\subsection{Pertuzumab}

\subsubsection{Metastatic Setting}

Pertuzumab is a monoclonal anti-body that impedes the heterodimerization between the HER2 and HER3 receptors [36] and was registered following the results of the CLEOPATRA trial [37], in which 127 patients (15.7\%) were 65 years of age or older. Pre-planned subgroup analyses by age group ( $<65, \geq 65,<75$, and $\geq 75$ years) suggest that all age groups benefit from the regimen similarly. Safety data show, however, a higher number of docetaxel dose reductions and lower total number of docetaxel cycles for the population $\geq 65$ years. Paradoxically, neutropenia was less common in older patients, likely because they received more growth factor support [38], but diarrhea (19\% vs $8 \%$ ) [39], anorexia, vomiting, dysgeusia and fatigue - all toxicities of significant functional impact in nutrition and hydration, were more common in older patients than in younger patients. An effective strategy to manage diarrhea should entail proactive follow-up and early intervention with antidiarrheal medications, dietary modifications, rehydration, dose delays, or reductions of the chemotherapy agent [40]. Additionally, a phase II trial showed that weekly paclitaxel, offers an alternative to docetaxel-based therapy for first and second-line older patients with BC [41].

The EORTC 75111-10114 randomized phase II evaluated trastuzumab combined with pertuzumab (TP) or TP plus metronomic chemotherapy (TPM - consisting of continuous $50 \mathrm{mg}$ cyclophosphamide) in an old/frail HER2 + metastatic BC population. The population consisted of a true older population; median age was 77 years and a potential frailty profile was present in 56 patients (71\%) of 79 as measured by the geriatric screening with the G8 tool $(\leq 14)$. With 20.7 months of median follow-up this study has shown a seven months higher median PFS for TPM over TP alone without adding significant toxicity in this old and frail HER2+ advanced BC population. This difference in treatment efficacy went along with an acceptable toxicity profile for both arms and geriatric assessment evolution during the first year showed no relevant difference in functional evolution between treatment arms [42] TPM constitutes, therefore, an alternative in this particularly frail population.

Regimens adding ET to the TP double are an interesting approach to older patients. In the PERTAIN study (aromatase inhibitor + trastuzumab + pertuzumab) patients received trastuzumab (with or without a taxane for 18-24 weeks) plus an aromatase inhibitor (anastrozole or letrozole), or trastuzumab (with or without a taxane for 18-24 weeks) plus pertuzumab and an aromatase inhibitor. Though double blockade plus aromatase inhibitor regimen appears to be effective, it is important to note that $57 \%$ of patients received induction chemotherapy (taxane) and thus it is strictly not possible to affirm TP without upfront taxane as a standard treatment option for the overall population of this study [43].

\subsubsection{Early Setting}

Pertuzumab is approved for use in the neoadjuvant setting (following the results of NEOSPHERE) and in adjuvant setting (APHINITY trial) [44-46]. No older-specific sub-analysis of these studies are available, and no studies in older patients using pertuzumab in the early setting have been published. Both studies have shown that pertuzumab causes a mild increase in toxicity when added to chemotherapy + trastuzumab - particularly diarrhea (mostly during chemotherapy) and rash. QoL results show meaningful declines in both the pertuzumab and placebo arms, with scores for diarrhea being the only significantly worse symptom in the pertuzumab group. A subgroup analysis of invasive diseasefree survival (iDFS) in APHINITY - presented as part of the main results suggests equivalent benefit for older patients - though still of marginal clinical meaning [46,47].

\subsection{Trastuzumab-emtansine (T-DM1)}

T-DM1 is an antibody drug conjugate approved for use in metastatic HER $2+$ BC following the results of the EMILIA and TH3RESA trials $[48,49]$. Both trials showed that T-DM1 was not only superior in terms of outcomes but less toxic than other treatment regimens. More recently, the KATHERINE trial has shown the benefit of T-DM1 in the post-neoadjuvant setting - which led to its rapid approval [50]. The most common grade 3/4 AEs reported with T-DM1 use were thrombocytopenia and liver enzyme elevation $[48,50]$.

A pooled safety analysis of T-DM1 trials including 122 older patients (defined as $\geq 65$ years of age) showed higher rate of grade 3-4 AEs in, as compared with patients with $<65$ years of age ( $51.6 \%$ vs $44 \%$, respectively) [51]. An interim subgroup analysis of the KAMILLA Trial (NCT01702571) focused on 373 older patients (defined as those with $\geq 65$ ) and confirms that patients $\geq 65$ have a higher rate of grade 3-4 AEs, as well as higher rate of treatment discontinuations due to AEs. The increase in grade 3-4 AEs was not due to a specific AE but rather to small increases in the incidence of many different AEs. The most common AEs among older patients included asthenia (any grade 29.5\%), nausea (27.6\%), fatigue (23.1\%), and decreased appetite (22.3\%). Thrombocytopenia of any grade occurred in $12.9 \%$ (3.5\% grade $\geq 3$ ) and haemorrhage in $23.9 \%$ of older patients ( $1.6 \%$ grade $\geq 3$ ) [52]. Cardiac toxicity, though generally not seen as associated with T-DM1, can still occur. A recent combined-analysis of 1961 patients showed that 66 patients experienced cardiac events, mostly low grade LVEF drops. Notably, age was a significant risk factor for cardiac events while using T-DM1 [53].

In the aforementioned EORTC-75111 randomized phase II trial, patients who had disease progression after TP or TPM were offered treatment with T-DM1. Among the 29 patients who continued on T-DM1, fifteen patients progressed, four patients died without progression and the median PFS after starting T-DM1 was about six months. During treatment, at least one grade 3-5 adverse event was reported in fourteen $(48 \%)$ of the 29 patients. One patient died because of pneumonitis and one due to cachexia.

The thrombocytopenia associated with T-DM1 is caused by DM1 interference with the differentiation of megakaryocytes [54]. It is important to note that, though thrombocytopenia and coagulopathies are not considered a normal part of the aging process, multiple drugs used in older patients can cause thrombocytopenia and therefore should be used with care in tandem with T-DM1 (including furosemide, thiazide diuretics, ranitidine, aspirin, and anticoagulants). Lastly, older patients are at a higher risk for gastro-intestinal comorbidities which predispose to bleeding (such as diverticular disease and gastric ulcers) and with a higher risk of hospitalization and death [55]. 


\subsection{Neratinib}

Neratinib is an oral, irreversible pan-HER TKI inhibitor and was approved following the results of the ExteNET trial testing one year of neratinib following standard adjuvant treatment, based on a significant yet small improvement in iDFS in the ITT population (2.3\%) though a higher iDFS improvement was seen in the HR+ cohort (4.4\%) [56]. Importantly, neratinib significantly increased the risk of diarrhea (grade 3 $=40 \%$ vs $2 \%$ in placebo arm) [56]. Systematic loperamide use with neratinib is now, therefore, considered as standard of care [57].

No data is yet available on older patients being treated with neratinib. Because of changes in body composition and loss of kidney function, diarrhea can be a significant problem for older patients [58]. Additionally, neratinib is major substrate of CYP3A4 and inhibitor of Pglycoprotein, leading to numerous drug-drug interactions, including with ciprofloxacin, digoxin and proton pump inhibitors. Taking all the currently available data, neratinib should not be considered as standard extended therapy for the general older population. There is an ongoing clinical trial to assess the safety and tolerability of neratinib treatment in patients with metastatic HER2-positive BC who are $\geq 60$ years of age (NCT02673398).

\section{3. mTOR Inhibitors}

The PI3K/AKT/mTOR pathway is often implicated in primary and secondary resistance to endocrine treatment [59]. Therefore, drugs targeting this pathway are being extensively investigated [59]. Recently, after the severe toxicity associated with pan-PI3K inhibitors, such as buparlisib, most attention has been focused on testing alfa-specific PI3K inhibitors in PIK3CA-mutant tumors [60,61]. Alpelisib is, for the time being, the only clinically active drug in this class despite a substantial toxicity profile, as shown in the SOLAR-1 trial [62]. The mTOR inhibitor everolimus remains, for the time being, the sole approved drug targeting this pathway.

\subsection{Everolimus}

Everolimus was approved in combination with exemestane for treatment in patients having failed to a non-steroidal aromatase inhibitor (AI) alone after the results of the BOLERO-2 trial. Out of a total of 724 patients the BOLERO-2 trial [63,64], 275 were $\geq 65,164$ were $\geq 70$ and 71 were $\geq 75$ years. In a subgroup analysis, patients $\geq 70$ years were shown to derive significant benefit from everolimus (absolute gain in PFS of 5.26 months, HR $0.45 ; 95 \%$ CI $0.38-0.54 ; P<.0001$ ) [65]. The toxicity profile was overall similar to younger patients, with the most common AEs being stomatitis, fatigue, decreased appetite, and diarrhea. However older patients in the everolimus arm more commonly had decreased appetite, dyspnea, anemia, asthenia, increased creatinine levels, and urinary tract infections than younger patients. Also clinically significant was the mean weight loss of $4.8 \mathrm{~kg}$ among older patients receiving everolimus with exemestane (vs $1.7 \mathrm{~kg}$ with placebo). Though dose reductions were no more common in the older sub-group (67\% for both age groups), treatment discontinuation due to $\mathrm{AE}(17.4 \% \mathrm{vs} 6.3 \%)$ and voluntary withdrawal (19\% vs $6.3 \%$ ) were both more common in this group. Also, the number of serious AEs attributed to study treatment increased ten-fold ( $11 \%$ vs $1 \%$ ), and patients using everolimus had an increased probability of fatal AEs, notably if $\geq 70$ years $[65,66]$.

The clinical significance of everolimus toxicity, therefore, cannot be ignored and is, in terms of magnitude, very similar to that of capecitabine, as the results of BOLERO- 6 suggest (incidence of grade 3 and 4 AEs $74 \%$ vs 70 s and of serious AEs $29 \%$ vs $36 \%$ in capecitabine and everolimus + examestane, respectively) [67]. Starting with a lower dose of $5 \mathrm{mg}$ (and dose increase if well tolerated) may represent a good strategy to avoid clinical complications. Stomatitis prophylaxis with steroid mouthwash should be used systematically, and attention should be taken with patient hydration and nutritional status [68].

\section{Anti-angiogenics}

Angiogenesis is one of the critical elements of the development of $\mathrm{BC}$ [69]. Bevacizumab, a humanized monoclonal antibody that targets VEGF-A in circulation, is for the time being the most extensively studied antiangiogenic agent in $\mathrm{BC}$, although it is currently not approved in the US due to a lack of benefit [70].

\subsection{Bevacizumab}

Given the lack of overall survival (OS) benefit, and the potential for increased toxicity, there is no evidence to support the use of bevacizumab in patients with metastatic BC. However, data is available on the comparative efficacy and toxicity of bevacizumab in older patients due to its long time in clinical use, and its approval for multiple diseases. In $\mathrm{BC}$, a sub-analysis of the AVADO trial was conducted on 127 patients aged $\geq 65$. Although the PFS benefit was not significant, it was numerically similar to the overall population results, and likely negative due to the small number of patients. Importantly, older patients did not seem to be at a higher risk of hypertension, proteinuria or cardiac events, with the number of neutropenia cases being the only toxicity with higher incidence in older patients [71]. These results bear a marked difference to the ATHENA trial investigating the safety of bevacizumab, which showed a greater incidence of grade 3 hypertension and proteinuria in older patients [72]. In both studies, the levels of bleeding, cardiac dysfunction and embolic events remained low overall, and similar in both younger and older patients.

\section{CDK 4/6 Inhibitors}

CDK 4/6 plays an important part in the regulation of the cell cycle [73]. The data on the oral CDK 4/6 inhibitors have led to considerable excitement, due to the improvement in PFS outcomes in combination with ET. Currently, this class has three approved agents - palbociclib, ribociclib and abemaciclib for use in patients with metastatic BC [74-77].

\subsection{Palbociclib}

Palbociclib is currently approved for use in first-line advanced ER+/ HER2- BC in combination with letrozole, and in patients who have failed at least one line of ET in combination with fulvestrant. This approval was based on the PFS results of three pivotal trials - PALOMA-1, 2 and 3 $[74,78,79]$. The most common and clinically significant adverse event was neutropenia ( $66.4 \%$ of patients with grade 3 or 4 ). Febrile neutropenia was a rare event across the various trials.

Rugo et al conducted a combined analysis of efficacy and toxicity in patients with patients aged $\geq 65$ in all Phase II and III trials of palbociclib. Among a total of 872 patients, 221 (25\%) were between 65 and 74 years and 83 (10\%) were $\geq 75$ years. Their results confirm that palbociclib improves outcomes in all age groups. AEs in older patients were similar to those of younger patients - with neutropenia being the more common but rarely complicated by febrile neutropenia events. Patients in the $\geq 75$ group, however, were at a significantly higher risk for myelosuppression [80].

Neutropenia is a major clinical issue, especially in older patients, as they are already infection-prone due to multiple factors. Even if febrile neutropenia levels remained overall low, it is important to note that $62 \%$ of patients between ages $65-74$ and $60 \%$ aged $\geq 75$ experienced infections during treatment. Though this number is close to that of younger patients (56\%), infections among older patients, especially if they require hospitalization, may trigger delirium and cognitive dysfunction with acute functional decline which can lead to long-term sequelae [81].

OS benefit with the use of CDK 4/6 inhibitors remains to be shown. In PALOMA-3, no significant improvement was found, as the trial was underpowered, despite an absolute difference of 6.9 months [82]. 
Furthermore, no strategy to select patients to use palbociclib is currently available. Since CDK 4/6 inhibitors are costly and can have toxic effects, especially in older patients, trials such as SONIA (NCT03425838) are currently investigating whether sequence matters when using CDK 4/ 6 inhibitors.

\subsection{Ribociclib}

Ribociclib was recently approved by the FDA for ER+/HER2- advanced $\mathrm{BC}$ in combination with letrozole, based on the results of the phase III randomized, double blind, placebo controlled MONALEESA-2 trial. Results showed a significant improvement in PFS as well as in other efficacy outcomes [75]. As expected, the most common grade $3 /$ 4 AEs were neutropenia and leukopenia. A subsequent sub-group analysis focused on older patients alone, defined as age $\geq 65$, including 295 patients ( $44 \%$ of the total sample) found that a comparable number of patients in both age groups had discontinued due to AEs (respectively $7 \%$ and $9 \%$ ) and that these were overall more common among older patients [83]. As ribociclib seems to prolong the QTc interval in a concentration-dependent manner, this treatment should be avoided in patients who already have QTC prolongation and in those using drugs known to prolong QTc. Special focus should be given to perform baseline ECG and repeat it during follow-up. Additionally, electrolytes should be measured, and drugs that can increase QTc should be avoided. For older patients, this is cause for concern as commonly used drugs can increase QTc. Advanced age, renal impairment, use of diuretics, and heart comorbidities are also risk factors for a prolonged QTc.

\subsection{Abemaciclib}

Abemaciclib differs from other CDK4/6 inhibitors by having a greater selectivity for CDK4. In practice, this translates into a continuous dosing schedule [84]; and important changes in the toxicity profile. In the registration MONARCH-3 trial diarrhea (any grade) occurred in $81.3 \%$ of patients (vs $29.8 \%$ in the control arm), neutropenia in $41.3 \%$ (vs $1.9 \%$ ), fatigue $40.1 \%$ (31.7\%) and vomiting $28.4 \%$ (vs $11.8 \%$ ) [76]. Additionally, venous thromboembolic events occurred in $4.9 \%$ of patients in the abemacicilib arm vs $0.6 \%$ in the control arm. For older patients, this toxicity profile is particularly problematic - notably the increased incidence of VTEs, as older patients are often less mobile and already have a baseline increased risk of VTEs [85], though it is important to note that this could be a class concern rather than an abemaciclib concern.

Therefore, when a CDK inhibitor is considered for an older patient, palbociclib might be a better treatment option until further data specific to older patients is available. Abemaciclib, with adequate management of diarrhoea, can also be an interesting option as the continuous administration can reduce the risk of mistakes for patients with cognitive issues.

\section{PARP Inhibitors}

Poly ADP ribose polymerases (PARP) are a group of proteins that are vital to the process of DNA repair [86]. In clinical practice, this principle has been explored in patients harboring BRCA germline mutations, who typically develop BC at a very early age. This is well exemplified by the median age in the registration trials of the two approved PARP inhibitors for BC- Olaparib and Talazoparib, which were respectively 44 and 45. Both drugs drugs have been tested in BRCA mutant populations with advanced BC against treatment of physician's choice, and have shown superior clinical and patient-reported outcomes (including QoL), despite substantial toxicity which includes anemia, neutropenia, fatigue and nausea [87-89]. Therefore, some older women may profit from the comparative QoL benefits of PARP inhibitors, as long as nausea and vomiting are proactively handled and CYP3A inhibitors (for Olaparib) and their substrates are avoided (see Table 3 ).

\section{Conclusion}

Globally, data on the efficacy and safety of targeted agents in older patients is of limited quality. Older patients are underrepresented in clinical trials, and those that do participate are likely to be fit based on performance status. End-points and follow-up are not well suited to the needs of older patients. In order to advance in increasing the options available for the treatment of older patients, trials geared at this population are essential. Integrating the geriatric assessment in clinical trials will allow for a better understanding of older participants [90]. Also, recruitment in clinical trials of older patients might improve with the recommendations from ASCO and Friends of Cancer Research initiative, which strongly suggest less stringent inclusion criteria for patients with organ dysfunction, prior malignancies, and comorbidities [91].

Supplementary data to this article can be found online at https://doi. org/10.1016/j.jgo.2019.05.012.

\section{Conflicts of Interest}

Dr. Noam Pondé has received travelling support from Roche/Genentech, Janssen-Cilag and Mundipharma, as well as speaker's fees from Mundipharma. The Institute he works for has received AstraZeneca, Lilly, MSD, Novartis, Pfizer, Roche-Genentech, Synthon, Radius and Servier.

Dr. Hans Wildiers received travel support from Roche and Pfizer, and his institution received consulting fees and honoraria from Roche, AstraZeneca, Amgen, Lilly, Novartis, Abbvie, Vifor Pharma, Pfizer, Celldex therapeutics, Janssen-CILAG, TRM Oncology, PUMA Biotechnology, ORION corporation and an unrestricted research grant from Roche. Dr. Ahmad Awada has acted as advior, received fees for lectures and research grants from Roche, Lilly, Amgen, ESAI, BMS, Pfizer, Novartis, MSD.

Dr. Evandro de Azambuja has received honoraria and advisory board from Roche/GNE, Travel grants from Roche/GNE and GSK/Novartis. The Institute he works for has received AstraZeneca, Lilly, MSD, Novartis, Pfizer, Roche-Genentech, Synthon, Radius and Servier. Coralie Deliens has no conflicts of interest to declare.

Dr. Lissandra Dal Lago has received travel grants from Roche/Genetench. The Institute she works for has received AstraZeneca, Lilly, MSD, Novartis, Pfizer, Roche-Genentech, Synthon, Radius and Servier.

\section{Authors Contribution}

Dr. Noam Pondé and Dr. Lissandra Dal Lago have conceived and written the original paper draft. Dr. Hans Wildiersn Ahmed Awada and Evandro de Azambuja have reviewed the manuscript, added content with their clinical experience and knlodge of the field. Coralie Deliens has contributed with pharmacological information on the different agents.

\section{References}

[1] Bray F, Ferlay J, Soerjomataram I, et al. Global cancer statistics 2018: GLOBOCAN estimates of incidence and mortality worldwide for 36 cancers in 185 countries: Global Cancer Statistics 2018 [Internet]. CA Cancer J Clin 2018. https://doi.org/10. 3322/caac.21492 [cited 2018 Oct 11] Available from.

[2] Belgian Cancer REgistry: Cancer Incidence Projections Belgium, 2015-2025 [Internet]. Available from http://www.kankerregister.org/media/docs/publications/ IncidenceProj2015-2025_finaal_171120.pdf.

[3] Bastiaannet E, Portielje JEA, van de Velde CJH, et al. Lack of survival gain for elderly women with breast cancer. Oncologist 2011;16:415-23.

[4] Le Saux O, Falandry C, Gan HK, et al. Inclusion of elderly patients in oncology clinical trials. Ann Oncol 2016 Sep;27(9):1799-804.

[5] Hurria A, Mohile SG, Dale W. Research priorities in geriatric oncology: addressing the needs of an aging population. J Natl Compr Cancer Netw JNCCN 2012:10:286-8.

[6] Wildiers H, Mauer M, Pallis A, et al. End points and trial design in geriatric oncology research: a joint european organisation for research and treatment of canceralliance for clinical trials in oncology-International Society of Geriatric Oncology Position Article. J Clin Oncol 2013:31:3711-8.

[7] Denduluri N, Chavez-MacGregor M, Telli ML, et al. Selection of optimal adjuvant chemotherapy and targeted therapy for early breast cancer: ASCO clinical practice guideline focused update. J Clin Oncol Off J Am Soc Clin Oncol 2018;36:2433-43. 
[8] Curigliano G, Burstein HJ, P Winer E, et al. De-escalating and escalating treatments for early-stage breast cancer: the St. Gallen international expert consensus conference on the primary therapy of early breast cancer 2017. Ann Oncol Off J Eur Soc Med Oncol 2017;28:1700-12.

[9] Kaufman PA, Brufsky AM, Mayer M, et al. Treatment patterns and clinical outcomes in elderly patients with HER2-positive metastatic breast cancer from the registHER observational study. Breast Cancer Res Treat 2012;135:875-83.

[10] Griffiths RI, Lalla D, Herbert RJ, et al. Infused therapy and survival in older patients diagnosed with metastatic breast cancer who received trastuzumab. Cancer Invest 2011;29:573-84.

[11] Brollo J, Curigliano G, Disalvatore D, et al. Adjuvant trastuzumab in elderly with HER-2 positive breast cancer: a systematic review of randomized controlled trials. Cancer Treat Rev 2013;39:44-50.

[12] Moja L, Tagliabue L, Balduzzi S, et al. Trastuzumab containing regimens for early breast cancer [Internet]. The Cochrane Collaboration (ed) , Cochrane Database of Systematic Reviews. Chichester, UK: John Wiley \& Sons, Ltd; 2012. https://doi. org/10.1002/14651858.CD006243.pub2 [cited 2017 Jul 19] Available from:.

[13] Dall P, Lenzen G, Göhler T, et al. Trastuzumab in the treatment of elderly patients with early breast cancer: results from an observational study in Germany. J Geriatr Oncol 2015;6:462-9.

[14] Reeder-Hayes KE, Meyer AM, Hinton SP, et al. Comparative toxicity and effectiveness of trastuzumab-based chemotherapy regimens in older women with earlystage breast cancer. J Clin Oncol JCO 2016;434(2017):71.

[15] Sawaki M. Evaluation of trastuzumab without chemotherapy as a postoperative adjuvant therapy in HER2-positive elderly breast cancer patients: Randomized controlled trial (RESPECT). J Clin Oncol 201820 May;36(15_suppl):510.

[16] Kobayashi K. [P2-13-02] Patient-reported outcomes with trastuzumab monotherapy versus trastuzumab plus standard chemotherapy as a postoperative adjuvant therapy in HER2-positive elderly breast cancer patients (RESPECT): A randomized, open-label, phase 3 clinical trial; 2019.

[17] Takahashi M, Sawaki M, Hagiwara Y, et al. Analysis of cognitive function in elderly HER2-positive breast cancer patients receiving either trastuzumab monotherapy or trastuzumab plus chemotherapy as a postoperative adjuvant treatment: A cognitive function sub-study of a randomized, open-label, phase 3 clinical trial (RESPECT trial), in San Antonio, Texas; 2018

[18] Joensuu H, Kellokumpu-Lehtinen P-L, Bono P, et al. Adjuvant docetaxel or vinorelbine with or without trastuzumab for breast cancer. N Engl J Med 2006;354: 809-20.

[19] Lambertini M, Pondé NF, Solinas C, et al. Adjuvant trastuzumab: a 10-year overview of its benefit. Expert Rev Anticancer Ther 2017;17:61-74.

[20] Earl HM. PERSEPHONE: 6 versus 12 months (m) of adjuvant trastuzumab in patients (pts) with HER2 positive $(+)$ early breast cancer (EBC): Randomised phase 3 non-inferiority trial with definitive 4-year (yr) disease-free survival (DFS) results [Slide set] J Clin Oncol 201820 May;36(15_suppl):506; 201820 May.

[21] Tolaney SM, Barry WT, Guo H, et al. Seven-year (yr) follow-up of adjuvant paclitaxel (T) and trastuzumab (H) (APT trial) for node-negative, HER2-positive breast cancer (BC). J Clin Oncol 2017;35:511.

[22] Lazzarini V, Mentz RJ, Fiuzat M, et al. Heart failure in elderly patients: distinctive features and unresolved issues. Eur J Heart Fail 2013;15:717-23.

[23] de Azambuja E, Procter MJ, van Veldhuisen DJ, et al. Trastuzumab-associated cardiac events at 8 years of median follow-up in the Herceptin adjuvant trial (BIG 101). J Clin Oncol Off J Am Soc Clin Oncol 2014;32:2159-65.

[24] Jawa Z, Perez RM, Garlie L, et al. Risk factors of trastuzumab-induced cardiotoxicity in breast cancer: a meta-analysis. Medicine (Baltimore) 2016;95:e5195.

[25] Chavez-MacGregor M, Zhang N, Buchholz TA, et al. Trastuzumab-related cardiotoxicity among older patients with breast cancer. J Clin Oncol Off J Am Soc Clin Oncol 2013;31:4222-8.

[26] Sawaki M, Mukai H, Tokudome N, et al. Safety of adjuvant trastuzumab for HER-2overexpressing elderly breast cancer patients: a multicenter cohort study. Breast Cancer 2012;19:253-8

[27] Meeting library | meta-analysis of the cardiac events in the adjuvant trastuzumab trials. [Internet]. [cited 2018 Dec 10] Available from https://meetinglibrary.asco. org/record/162927/abstract.

[28] Johnston S, Pippen J, Pivot X, et al. Lapatinib combined with letrozole versus letrozole and placebo as first-line therapy for postmenopausal hormone receptor-positive metastatic breast cancer. J Clin Oncol Off J Am Soc Clin Oncol 2009;27:5538-46.

[29] Blackwell KL, Burstein HJ, Storniolo AM, et al. Randomized study of Lapatinib alone or in combination with Trastuzumab in women with ErbB2-positive, Trastuzumabrefractory metastatic breast Cancer. J Clin Oncol 2010;28:1124-30.

[30] Geyer CE, Forster J, Lindquist D, et al. Lapatinib plus Capecitabine for HER2-positive advanced breast Cancer. N Engl J Med 2006;355:2733-43.

[31] Cetin B, Benekli M, Dane F, et al. Lapatinib plus Capecitabine for HER2-positive advanced-stage breast Cancer in elderly women: review of the Anatolian Society of Medical Oncology (ASMO) experience. Breast Care 2013;8:67-70.

[32] Piccart-Gebhart M, Holmes E, Baselga J, et al. Adjuvant Lapatinib and Trastuzumab for early human epidermal growth factor receptor 2-positive breast Cancer: results from the randomized phase III adjuvant Lapatinib and/ or Trastuzumab treatment optimization trial. J Clin Oncol Off J Am Soc Clin Oncol 2016;34:1034-42.

[33] O'Connor T. Tolerability of the combination of lapatinib and trastuzumab in older patients with HER2 positive metastatic breast cancer; 2018.

[34] Dranitsaris G, Lacouture ME. Development of prediction tools for diarrhea and rash in breast cancer patients receiving lapatinib in combination with capecitabine. Breast Cancer Res Treat 2014;147:631-8.
[35] Mislang AR, Wildes TM, Kanesvaran R, et al. Adherence to oral cancer therapy in older adults: the International Society of Geriatric Oncology (SIOG) taskforce recommendations. Cancer Treat Rev 2017;57:58-66.

[36] Capelan M, Pugliano L, De Azambuja E, et al. Pertuzumab: new hope for patients with HER2-positive breast cancer. Ann Oncol 2013;24:273-82.

[37] Swain SM, Baselga J, Kim S-B, et al. Pertuzumab, trastuzumab, and docetaxel in HER2-positive metastatic breast cancer. N Engl J Med 2015;372:724-34.

[38] Miles D, Baselga J, Amadori D, et al. Treatment of older patients with HER2-positive metastatic breast cancer with pertuzumab, trastuzumab, and docetaxel: subgroup analyses from a randomized, double-blind, placebo-controlled phase III trial (CLEOPATRA). Breast Cancer Res Treat 2013;142:89-99.

[39] Swain SM, Schneeweiss A, Gianni L, et al. Incidence and management of diarrhea in patients with HER2-positive breast cancer treated with pertuzumab. Ann Oncol 2017 April;28(4):761-8 (mdw695).

[40] Melosky B. Supportive care treatments for toxicities of anti-egfr and other targeted agents. Curr Oncol Tor Ont 2012;19:S59-63.

[41] Smyth LM, Iyengar NM, Chen MF, et al. Weekly paclitaxel with trastuzumab and pertuzumab in patients with HER2-overexpressing metastatic breast cancer: overall survival and updated progression-free survival results from a phase II study. Breast Cancer Res Treat 2016;158:91-7.

[42] Wildiers H, Tryfonidis K, Dal Lago L, et al. Pertuzumab and trastuzumab with or without metronomic chemotherapy for older patients with HER2-positive metastatic breast cancer (EORTC 75111-10114): an open-label, randomised, phase 2 tria from the elderly task force/breast Cancer group. Lancet Oncol 2018;19:323-36.

[43] Rimawi M, Ferrero J-M. First-line Trastuzumab plus an aromatase inhibitor, with or without Pertuzumab. In: de la Haba-Rodriguez J, et al, editors. Human epidermal growth factor receptor 2-positive and hormone receptor-positive metastatic or locally advanced breast Cancer (PERTAIN): A randomized, open-label phase II trial; 2018 J Clin Oncol Off J Am Soc Clin Oncol JCO2017767863.

[44] Gianni L, Pienkowski T, Im Y-H, et al. Efficacy and safety of neoadjuvant pertuzumab and trastuzumab in women with locally advanced, inflammatory, or early HER2-positive breast cancer (NeoSphere): a randomised multicentre, openlabel, phase 2 trial. Lancet Oncol 2012;13:25-32.

[45] Gianni L, Pienkowski T, Im Y-H, et al. 5-year analysis of neoadjuvant pertuzumab and trastuzumab in patients with locally advanced, inflammatory, or early-stage HER2-positive breast cancer (NeoSphere): a multicentre, open-label, phase 2 randomised trial. Lancet Oncol 2016;17:791-800.

[46] von Minckwitz G, Procter M, de Azambuja E, et al. Adjuvant Pertuzumab and Trastuzumab in early HER2-positive breast Cancer. N Engl J Med 2017;377:122-31.

[47] Baselga J. Patient (pt)-reported function and symptoms in APHINITY: A randomized comparison of chemotherapy $(\mathrm{C})+$ trastuzumab $(\mathrm{H})+$ placebo (Pla) versus $\mathrm{C}+\mathrm{H}+$ pertuzumab $(\mathrm{P})$ as adjuvant therapy in pts with HER2-positive early breast cancer (EBC). J Clin Oncol 201820 May;36(15_suppl):521.

[48] Verma S, Miles D, Gianni L, et al. Trastuzumab Emtansine for HER2-positive advanced breast Cancer. N Engl J Med 2012;367:1783-91

[49] Krop IE, Kim S-B, González-Martín A, et al. Trastuzumab emtansine versus treatment of physician's choice for pretreated HER2-positive advanced breast cancer (TH3RESA): a randomised, open-label, phase 3 trial. Lancet Oncol 2014; 15:689-99.

[50] von Minckwitz G, Huang C-S, Mano MS, et al. Trastuzumab emtansine for residua invasive HER2-positive breast cancer [Internet]. N Engl J Med 2018. https://doi.org/ 10.1056/NEJMoa1814017 [cited 2018 Dec 10] Available from.

[51] Diéras V, Harbeck N, Budd GT, et al. Trastuzumab emtansine in human epidermal growth factor receptor 2-positive metastatic breast cancer: an integrated safety analysis. J Clin Oncol 2014;32:2750-7.

[52] Barrios, et al. Safety of trastuzumab emtansine (T-DM1) in 373 patients 65 years or older with HER2-positive advanced breast cancer: a subgroup analysis of the Kamilla study. J Clin Oncol 201520 May;33(15_suppl):603.

[53] Pondé N. Trastuzumab Emtansine (T-DM1) associated cardiac toxicity: pooled analysis of 7 trials, in Chicago, USA. ASCO 2018.

[54] Uppal H, Doudement E, Mahapatra K, et al. Potential mechanisms for thrombocytopenia development with Trastuzumab Emtansine (T-DM1). Clin Cancer Res 2015; 21:123-33.

[55] Yachimski PS, Friedman LS. Gastrointestinal bleeding in the elderly. Nat Clin Pract Gastroenterol Hepatol 2008;5:80-93.

[56] Chan A, Delaloge S, Holmes FA, et al. Neratinib after trastuzumab-based adjuvant therapy in patients with HER2-positive breast cancer (ExteNET): a multicentre, randomised, double-blind, placebo-controlled, phase 3 trial. Lancet Oncol 2016; 17:367-77.

[57] Chan A. Neratinib in HER-2-positive breast cancer: results to date and clinical usefulness. Ther Adv Med Oncol 2016;8:339-50.

[58] Wildiers H, Highley MS, de Bruijn EA, et al. Pharmacology of anticancer drugs in the elderly population. Clin Pharmacokinet 2003;42:1213-42.

[59] Ciruelos Gil EM. Targeting the PI3K/AKT/mTOR pathway in estrogen receptorpositive breast cancer. Cancer Treat Rev 2014;40:862-71.

[60] Baselga J, Im S-A, Iwata H, et al. Buparlisib plus fulvestrant versus placebo plus fulvestrant in postmenopausal, hormone receptor-positive, HER2-negative, advanced breast cancer (BELLE-2): a randomised, double-blind, placebo-controlled phase 3 trial. Lancet Oncol 2017:18:904-16.

[61] Di Leo A, Johnston S, Lee KS, et al. Buparlisib plus fulvestrant in postmenopausa women with hormone-receptor-positive, HER2-negative, advanced breast cancer progressing on or after mTOR inhibition (BELLE-3): a randomised, double-blind, placebo-controlled, phase 3 trial. Lancet Oncol 2018;19:87-100.

[62] André F. Alpelisib + Fulvestrant for HR+, HER2- advanced breast cancer: Results of the phase III SOLAR-1 trial. ESMO 2018.

[63] Piccart M, Hortobagyi GN, Campone M, et al. Everolimus plus exemestane for hormone-receptor-positive, human epidermal growth factor receptor-2-negative 
advanced breast cancer: overall survival results from BOLERO-2. Ann Oncol 2014; 25:2357-62.

[64] Baselga J, Campone M, Piccart M, et al. Everolimus in postmenopausal hormone-receptor-positive advanced breast Cancer. N Engl J Med 2012;366:520-9.

[65] Pritchard KI, Burris HA, Ito Y, et al. Safety and efficacy of Everolimus with Exemestane vs. Exemestane alone in elderly patients with HER2-negative, hormone receptor-positive breast Cancer in BOLERO-2. Clin Breast Cancer 2013;13: 421-432.e8.

[66] Wesolowski R, Abdel-Rasoul M, Lustberg M, et al. Treatment-related mortality with everolimus in cancer patients. Oncologist 2014;19:661-8.

[67] Jerusalem G, de Boer RH, Hurvitz S, et al. Everolimus plus exemestane vs everolimus or capecitabine monotherapy for estrogen receptor-positive, HER2-negative advanced breast cancer: The BOLERO-6 randomized clinical trial JAMA Oncol e182262; 2018.

[68] Rugo HS, Seneviratne L, Beck JT, et al. Prevention of everolimus-related stomatitis in women with hormone receptor-positive, HER2-negative metastatic breast cancer using dexamethasone mouthwash (SWISH): a single-arm, phase 2 trial. Lancet Oncol 2017; 18:654-62.

[69] Hanahan D, Weinberg RA. Hallmarks of cancer: the next generation. Cell 2011;144: 646-74.

[70] Miles D, Chan A, Romieu G, et al. Final overall survival (OS) results from the randomised, double-blind, placebo-controlled, phase III AVADO study of bevacizumab (BV) plus Docetaxel (D) compared with placebo (PL) plus D for the first-line treatment of locally recurrent (LR) or metastatic breast cancer (mBC). Cancer Res 2009;69:41.

[71] Pivot X, Schneeweiss A, Verma S, et al. Efficacy and safety of bevacizumab in combination with docetaxel for the first-line treatment of elderly patients with locally recurrent or metastatic breast cancer: results from AVADO. Eur J Cancer Oxf Engl 1990 2011:47:2387-95.

[72] Biganzoli L, Di Vincenzo E, Jiang Z, et al. First-line bevacizumab-containing therapy for breast cancer: results in patients aged $\geq 70$ years treated in the ATHENA study. Ann Oncol 2012;23:111-8.

[73] Finn RS, Aleshin A, Slamon DJ. Targeting the cyclin-dependent kinases (CDK) 4/6 in estrogen receptor-positive breast cancers [Internet]. Breast Cancer Res 2016;18 [cited 2016 Feb 17] Available from http://breast-cancer-research.com/content/18/ $1 / 17$.

[74] Turner NC, Ro J, André F, et al. Palbociclib in hormone-receptor-positive advanced breast Cancer. N Engl J Med 2015;373:209-19.

[75] Hortobagyi GN, Stemmer SM, Burris HA, et al. Ribociclib as first-line therapy for HR-positive, advanced breast Cancer. N Engl J Med 2016;375:1738-48.

[76] Goetz MP, Toi M, Campone M, et al. MONARCH 3: Abemaciclib as initial therapy for advanced breast Cancer. J Clin Oncol 2017;35:3638-46

[77] Battisti NML, De Glas N, Sedrak MS, et al. Use of cyclin-dependent kinase 4/6 (CDK4/6) inhibitors in older patients with ER-positive HER2-negative breast cancer: young International Society of Geriatric Oncology review paper. Ther Adv Med Oncol 2018;10:1758835918809610.

[78] Finn RS, Crown JP, Lang I, et al. The cyclin-dependent kinase 4/6 inhibitor palbociclib in combination with letrozole versus letrozole alone as first-line treatment of oestrogen receptor-positive, HER2-negative, advanced breast cancer (PALOMA-1/TRIO-18): a randomised phase 2 study. Lancet Oncol 2015;16:25-35.

[79] Finn RS, Martin M, Rugo HS, et al. Palbociclib and Letrozole in advanced breast Cancer. N Engl J Med 2016;375:1925-36.

[80] Rugo HS, Turner NC, Finn RS, et al. Palbociclib plus endocrine therapy in older women with HR +/HER2- advanced breast cancer: a pooled analysis of randomised PALOMA clinical studies. Eur J Cancer Oxf Engl 1990 2018;101:123-33.

[81] Inouye SK, Westendorp RG, Saczynski JS. Delirium in elderly people. Lancet 2014; 383:911-22.

[82] Turner NC, Slamon DJ, Ro J, et al. Overall survival with Palbociclib and Fulvestrant in advanced breast Cancer. N Engl J Med 2018;379:1926-36.
[83] Sonke GS. Efficacy and safety of ribociclib (LEE011) + letrozole in elderly patients with hormone receptor-positive (HR+), HER2-negative (HER2-) advanced breast cancer (ABC) in MONALEESA-2. ECCO 2018.

[84] McCartney A, Moretti E, Sanna G, et al. The role of abemaciclib in treatment of advanced breast cancer. Ther Adv Med Oncol 2018;10:175883591877692.

[85] Lacut K, Le Gal G, Mottier D. Primary prevention of venous thromboembolism in elderly medical patients. Clin Interv Aging 2008;3:399-411.

[86] Morales J, Li L, Fattah FJ, et al. Review of poly (ADP-ribose) polymerase (PARP) mechanisms of action and rationale for targeting in cancer and other diseases. Crit Rev Eukaryot Gene Expr 2014;24:15-28.

[87] Robson M, Im S-A, Senkus E, et al. Olaparib for metastatic breast Cancer in patients with a Germline BRCA mutation. N Engl J Med 2017;377:523-33.

[88] Litton JK, Rugo HS, Ettl J, et al. Talazoparib in patients with advanced breast Cancer and a Germline BRCA mutation. N Engl J Med 2018;379:753-63.

[89] Robson M. EORTC QLQ-C30 symptoms in patients with HER2-negative metastatic breast cancer and a germline BRCA mutation receiving olaparib versus chemotherapy treatment of physician's choice in OlympiAD. ESMO 2017.

[90] European Medicines Agency. Reflection paper on physical frailty: Instruments for baseline characterisation of older populations in clinical trials; 2017.

[91] Lichtman SM, Harvey RD, Damiette Smit M-A, et al. Modernizing clinical trial eligibility criteria: recommendations of the American Society of Clinical Oncologyfriends of Cancer research organ dysfunction, prior or concurrent malignancy, and comorbidities working group. J Clin Oncol 2017;35:3753-9.

[92] Kaufman B, Mackey JR, Clemens MR, et al. Trastuzumab plus Anastrozole versus Anastrozole alone for the treatment of postmenopausal women with human epidermal growth factor receptor 2-positive, hormone receptor-positive metastatic breast Cancer: results from the randomized phase III TAnDEM study. J Clin Oncol 2009;27:5529-37.

[93] Slamon DJ, Leyland-Jones B, Shak S, et al. Use of chemotherapy plus a monoclonal antibody against HER2 for metastatic breast cancer that overexpresses HER2. N Engl J Med 2001;344:783-92.

[94] Piccart-Gebhart MJ, Procter M, Leyland-Jones B, et al. Trastuzumab after adjuvant chemotherapy in HER2-positive breast cancer. N Engl J Med 2005;353:1659-72.

[95] Slamon D, Eiermann W, Robert N, et al. Adjuvant Trastuzumab in HER2-positive breast Cancer. N Engl J Med 2011;365:1273-83.

[96] Spielmann M, Roche H, Delozier T, et al. Trastuzumab for patients with axillarynode-positive breast Cancer: results of the FNCLCC-PACS 04 trial. J Clin Oncol 2009;27:6129-34

[97] Gelmon KA, Boyle FM, Kaufman B, et al. Lapatinib or Trastuzumab plus Taxane therapy for human epidermal growth factor receptor 2-positive advanced breast Cancer: final results of NCIC CTG MA.31. J Clin Oncol 2015;33:1574-83.

[98] Baselga J, Campone M, Piccart M, et al. Everolimus in postmenopausal hormone-receptor-positive advanced breast Cancer. N Engl J Med 2012;366:520-9.

[99] Cristofanilli M, Turner NC, Bondarenko I, et al. Fulvestrant plus palbociclib versus fulvestrant plus placebo for treatment of hormone-receptor-positive, HER2negative metastatic breast cancer that progressed on previous endocrine therapy (PALOMA-3): final analysis of the multicentre, double-blind, phase 3 randomised controlled trial [Internet]. Lancet Oncol 201601 April;17(4):425-39.

[100] Hortobagyi GN, Stemmer SM, Burris HA, et al. Updated results from MONALEESA-2, a phase III trial of first-line ribociclib plus letrozole versus placebo plus letrozole in hormone receptor-positive, HER2-negative advanced breast cancer [Internet]. Ann Oncol 2018. https://doi.org/10.1093/annonc/mdy155/4989216 [cited 2018 May 28] Available from.

[101] Robert NJ, Diéras V, Glaspy J, et al. RIBBON-1: randomized, double-blind, placebocontrolled, phase III trial of chemotherapy with or without Bevacizumab for firstline treatment of human epidermal growth factor receptor 2-negative, locally recurrent or metastatic breast Cancer. J Clin Oncol 2011;29:1252-60.

[102] Miller K, Wang M, Gralow J, et al. Paclitaxel plus bevacizumab versus paclitaxel alone for metastatic breast cancer. N Engl J Med 2007;357:2666-76. 